\section{Rust-resistant sh2 Sweet Corn Populations}

\author{
Scot H. Hulbert ${ }^{2}$ and Jeff A. Drake \\ Department of Plant Pathology, Kansas State University, Manhattan, \\ KS 66506-5502
}

Additional index words. maize, Puccinia, rpl, durable resistance, Zea mays

The Rpl area, on the short arm of maize (Zea mays L.) chromosome 10, carries most of the major genes that have been identified for resistance to common rust (Puccinia sorghi) Schwein. These include the rpl complex, as well as $R p 5$ and $R p G$, which map 1-3 cM toward the telomere (Hulbert, 1997). The linkages among these genes enable the selection of recombinant individuals that carry $R p 5$ or $R p G$ and an $R p 1$ gene by screening families consisting of a several hundred testcross progeny with the appropriate rust biotypes. Different genes, or alleles, within the rpl-complex can also be recombined by screening larger populations. Once the appropriate alleles have been recombined into coupling phase, they can be manipulated as single genes in breeding programs.

Some of the recombinant rpl gene clusters, or "recombinant haplotypes," that have been generated confer high levels of resistance to all known common rust biotypes ( $\mathrm{Hu}$ and Hulbert, 1995). Some of the recombinant haplotypes appear to confer resistance that is broader than that expected from the component genes (Hu et al., 1997). The Rpl-DJ haplotype, which carries both $R p 1-J$ and $R p 1$ $D$, confers partial resistance to a biotype that was virulent on both parental genes and also showed partial resistance to southern rust $(P$. polysora Underw.). The extent to which other recombinant haplotypes confer general rust resistance has not been investigated. General resistance is impossible to evaluate for recombinant haplotypes that confer race-specific resistance to all known common rust biotypes because of the combination of $\mathrm{Rp}$ genes that they carry.

To expedite the development of sweet corn cultivars with potentially durable resistance, we previously crossed two recombinant haploytpes into sul sweet corn backgrounds (Hulbert et al., 1997). Here we describe the transfer of two recombinant haplotypes to $\operatorname{sh} 2$

\footnotetext{
Received for publication: 26 Oct. 1998. Accepted for publication 24 May 1999. We thank W.W. Bockus and L.E. Claflin for assistance in generating the sweet corn populations. Contribution No. 99161-J from the Dept. of Plant Pathology, Kansas Agricultural Experiment Station. This work was supported by a U.S. Dept. of Agriculture grant No. 9300604.The cost of publishing this paper was defrayed in part by the payment of page charges. Under postal regulations, this paper therefore must be hereby marked advertisement solely to indicate this fact.

${ }^{1}$ E-mail address: shulbrt@plantpath.ksu.edu
}

sweet corn backgrounds. Many sweet corn breeding programs are now using the sh 2 gene for sweetness. To promote the utilization of multiple sources of resistance in different cultivars, the two recombinant gene clusters transferred were different from those used previously. These populations will allow the transfer of rust resistance into existing lines with a minimal number of backcrosses and may also be suitable for the selection of parental lines for hybrid development.

\section{Origin and Description}

Genes conditioning resistance. All of the rust resistance genes utilized were originally in the R168 inbred background except for the Rpl-C gene, which was in the B14 background. The construction of the two recombinant haplotypes was described previously $(\mathrm{Hu}$ and Hulbert, 1995). Rp-GDJ4 has Rpl-J and $R p 1-D$ tightly linked at $\approx 0.1 \mathrm{cM}$, along with the $R p G$ gene, which maps $\approx 2 \mathrm{cM}$ distally. The $R p 1-F J C$ recombinant haplotype has $R p l-F$,
$R p 1-J$, and $R p 1-C$ linked in coupling phase. All three genes map within $0.2 \mathrm{cM}$ of each other. Both gene clusters provide resistance to all rust biotypes in our common rust collection (Hulbert et al., 1991). Lines carrying both recombinant haplotypes have also appeared to be resistant to common rust in our summer (1994 to 1998) nurseries at the Kansas State Univ. Rocky Ford Experimental Field, Manhattan, Kans., but we have made no effort to evaluate the diversity of endemic common rust populations in Kansas.

Origin of the populations. Two sweet corn populations were made by crossing each of the two compound $R p 1$ genes into a $s h 2$ sweet corn background. Lines carrying each of the two compound genes were crossed with the sweet corn hybrid 'Zenith' (Harris Moran, Salinas, Calif.) and rust-resistant plants were subsequently backcrossed to 'Zenith' two times (Fig. 1). Rust-resistant plants were selected in each generation by greenhouse inoculations of seedlings (Hulbert et al., 1991). Rust-resistant $\mathrm{BC}_{2}$ plants were then crossed with the hybrid 'Nordic' (Illinois Foundation Seed, Inc. Champaign, Ill.). Plants carrying each of the recombinant haplotypes were then selected and sib-mated. Two families derived from sibmating for each of the recombinant haplotypes were grown in a field nursery in Manhattan in 1997. Plants showing good vigor, intermediate ear height $(0.3-1.0 \mathrm{~m}$ from soil), few tillers and early maturity ( $<62 \mathrm{~d}$ to pollen shed) were self-pollinated. We also selected for the absence of chlorotic and necrotic spotting, which is associated with both of the compound genes in some genetic backgrounds (unpublished). $S_{1}$ families that were homozygous for each of

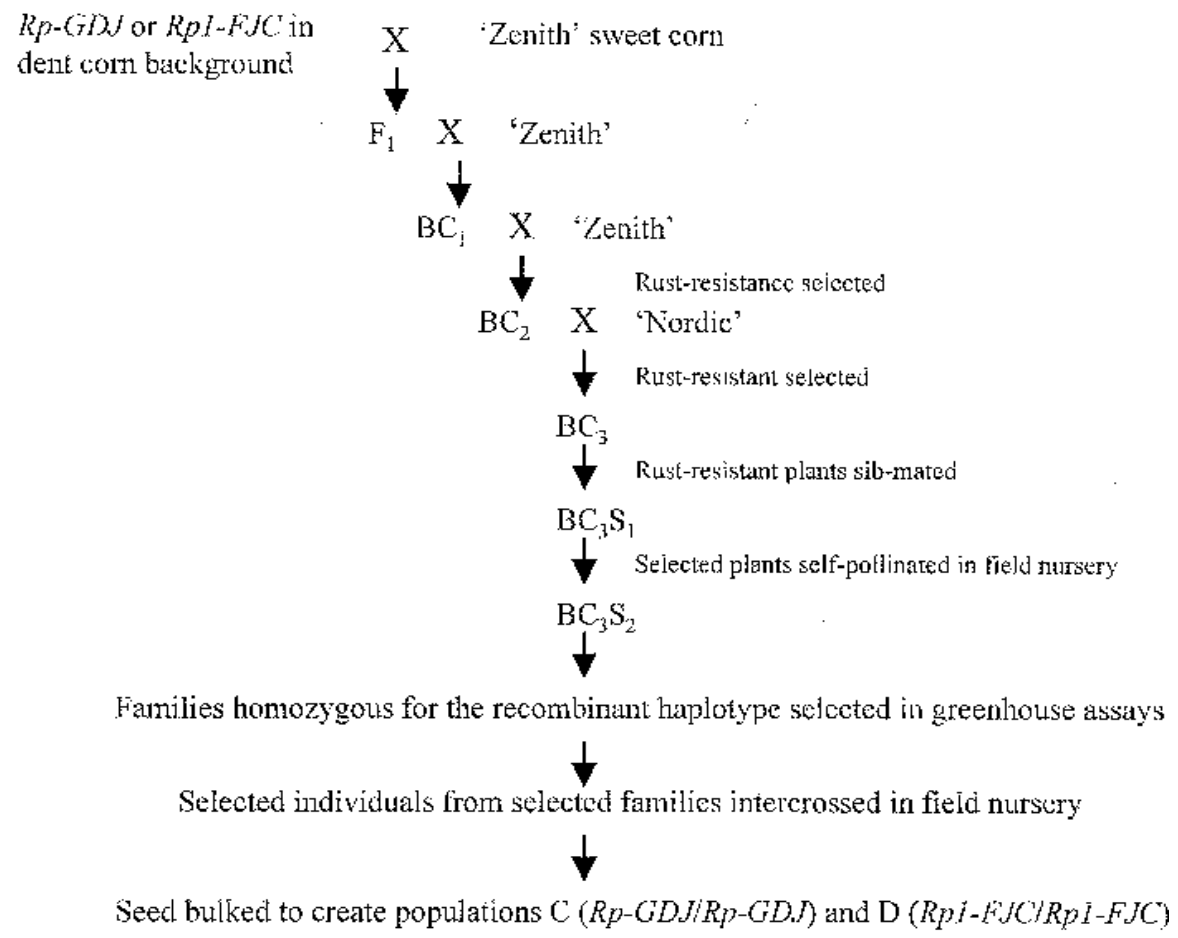

Fig. 1. Development of the rust-resistant sweet corn populations. The only difference in the pedigrees of the two populations is that a line carrying the $R p-G D J$ compound gene was used in the initial cross to generate population $\mathrm{C}$, while a line carrying $R p l-F J C$ was used to generate population D. 
the compound genes were identified by rust inoculations. Twelve selected families, homozygous for $R p-G D J$, were grown in a field nursery in Manhattan in 1998. Selected individuals in each family were individually crossed with selected individuals in the other families. Over 100 individual crosses were bulked to make “population C." Similarly, selected individuals from nine families homozygous for $R p 1$ -

$F J C$ were intercrossed and the resulting seed bulked to make "population D" (Fig. 1).

\section{Uses}

Populations $\mathrm{C}$ or $\mathrm{D}$ can be used to transfer the $R p-G D J$ or $R p l-F J C$ recombinant haplotypes into rust-susceptible sweet corn lines with minimal undesirable dent corn traits. Following crosses with rust-susceptible genotypes, the presence of the recombinant haplotypes may be detected with any known rust biotype, or can be assayed in the field under natural inoculation conditions.

\section{Availability}

Seed samples of populations $\mathrm{C}$ and D are available from S.H. Hulbert, Dept. of Plant Pathology, Throckmorton Hall, Kansas State University, Manhattan, KS 66506-5502 (email: shulbrt@plantpath.ksu.edu).

\section{Literature Cited}

Hu, G. and S.H. Hulbert. 1995. Construction of 'compound' rust resistance genes in maize. Euphytica 87:45-51.

Hu, G., C.A. Webb, and S.H.Hulbert. 1997. Adult-plant phenotype of the Rp1-DJ compound rust resistance gene in maize. Phytopathology 87:236-241.

Hulbert, S.H. 1997. Structure and evolution of the rp1 complex conferring rust resistance in maize. Annu. Rev. Phytopathol. 35:293-310.

Hulbert, S.H., G. Hu, and J.A. Drake. 1997. Kansas rust-resistant sweet corn populations A and B. HortScience 32:1130-1131.

Hulbert, S.H., P.C. Lyons, and J.L. Bennetzen. 1991. Reactions of maize lines carrying resistance to isolates of the common rust pathogen, Puccinia sorghi . Plant Dis. 75:1130-1133. 